\title{
NEW TECHNOLOGIES FOR THE DOCUMENTATION AND PRESERVATION OF THE MAYA CULTURAL HERITAGE. THE PALACE OF THE GOVERNOR AT UXMAL (YUCATÁN, MEXICO)
}

\author{
G. Muñoz Cosme ${ }^{1,3}$, C. Vidal Lorenzo ${ }^{2, *}$ \\ ${ }^{1}$ Departamento de Composición Arquitectónica, Universitat Politècnica de València, Valencia, Spain - gmcosme@upv.es \\ ${ }^{2}$ Departamento de Historia del Arte, Universitat de València, Valencia, Spain - cristina.vidal@uv.es \\ ${ }^{3}$ Research Centre PEGASO, Universitat Politècnica de València, Valencia, Spain
}

\section{Commission II - WG II/8}

KEY WORDS: $\quad$ Heritage, Digital Technologies, Documentation, Maya Culture.

\begin{abstract}
:
One of the major challenges currently facing the architectural and archaeological heritage in subtropical World Heritage sites is its preventive conservation. Many of these sites are vulnerable to the adverse impacts of natural disasters and climate change. The risk is compounded by the fact that several of them are among the most iconic places in the world, and so they also face the threat of the excessive growth of visitors. What is more, in earlier times many were restored with unsuitable materials or using inappropriate techniques which have heightened the risk they face today. However, thanks to the new digital technologies of architectural documentation involving the use of laser scanner and photogrammetry, applied in combination with traditional systems, the current state of the buildings can be documented and evaluated thoroughly and accurately. The information obtained can help to guide the choice of the measures and actions needed to prevent, or at least minimize, future deterioration or loss. An example of a project of this kind is the documentation work we are currently carrying out at the Palace of the Governor, an exceptional $98 \mathrm{~m}$ long building from the Late Classic period, located in the Maya city of Uxmal (Yucatán, Mexico). The palace is situated in a prominent position on a large, elevated platform. The results of this research are the subject of this paper.
\end{abstract}

\section{INTRODUCTION}

The successful conservation of architectural and archaeological heritage often requires the support and expertise of several disciplines - all the more so when this cultural heritage is situated in a very active natural environment like the subtropics, where cultural and natural heritage are inextricably entwined. In these regions the climatic and environmental conditions require additional measures to protect monuments and buildings from heavy rainfall and other extreme weather events, and also from the actions of aggressive flora and fauna.

In the case of a cultural heritage as vast as that of the Maya area, its safeguarding is not easy. Very often the Maya heritage has been the victim of looting and pillaging, motivated by the illicit trafficking of antiquities. These actions have had a devastating effect on the ancient buildings even before they could be excavated and studied.

In spite of these difficulties, an important Maya architectural heritage is preserved at the archaeological sites of Mexico, Guatemala, Belize, Honduras and El Salvador, under the stewardship of the local authorities. Many of these archaeological sites are renowned destinations for visitors and experts from all over the world, and eight of them have been included on UNESCO's World Heritage list for their outstanding universal value: one in El Salvador (Joya de Cerén); two in Guatemala (Tikal and Quiriguá), one in Honduras (Copán) and four in Mexico, (Palenque, Chichén Itzá, Uxmal and Calakmul). This recognition bears witness to the importance of this cultural legacy.

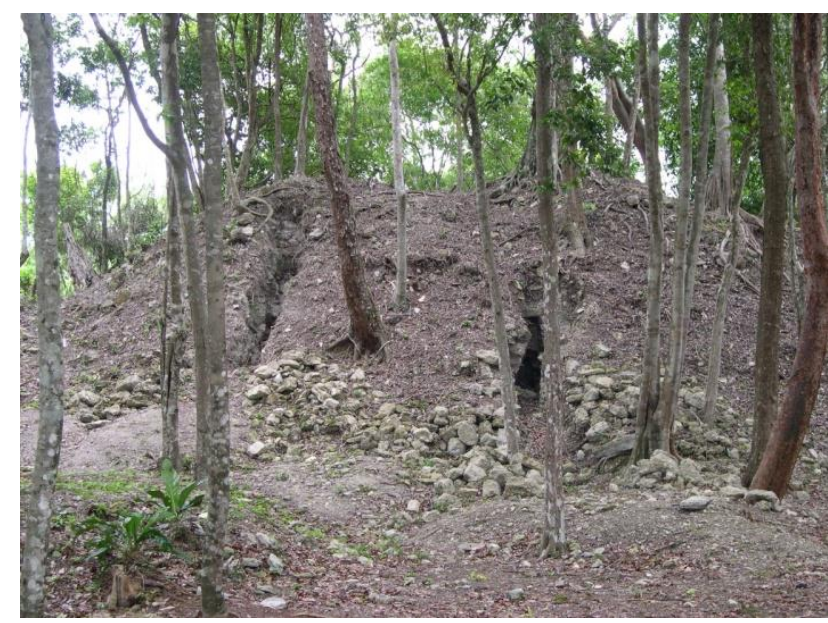

Figure 1. Looting trenches in an archaeological mound at Tzikín Tzakán, Petén, Guatemala. (Photo G. Muñoz 2005).

The preservation of this cultural heritage for present and future generations is a moral responsibility for the societies living in the area today. It also represents a major challenge. Innovative preventive conservation strategies need be developed that can establish a sustainable conservation system for the cultural heritage in general and for the architectural heritage in particular.

Actually, all the actions carried out, whether they involve research, intervention or conservation, must be framed inside a logic of sustainable development, in line with the United

\footnotetext{
* Corresponding author.
} 
Nations 2030 Agenda for Sustainable Development. This agenda is a universal call to action to end poverty, protect the planet, and improve the lives and prospects of all.

For this reason, we must first document and examine the architectural objects covered by this conservation plan, in order to evaluate their present state and to record the history of the conservation and restoration work already carried out. All this information is crucial to determine which preventive measures and conservation protocols should be applied in order to avoid situations of deterioration, which require more radical and traumatic (and undoubtedly more costly) interventions.

Preventive conservation has proved to be a successful strategy in archaeological sites, keeping the restoration and conservation work carried out to a minimum and also within budgetary limits. It is a strategy that guarantees the sustainability of conservation programs for cities, archaeological sites, and monumental architecture.

Three initial steps must be established for an adequate preventive conservation strategy:

1. Knowledge of the object and its history

2. Knowledge of its surroundings

3. Analysis of risks of deterioration

The final stage involves an assessment of the results and the economic and cultural sustainability of the project.

\section{THE DOCUMENTATION OF THE OBJECT}

The first of these steps (the in-depth examination of the architectural object in its current material state, as well as its history, both ancient and recent) is vital in order to obtain an adequate diagnosis that allows an evaluation of the risk of deterioration and thus be able to take decisions regarding definitive conservation strategies.

This first step, along with the second step (knowledge of the surroundings), are fundamental in order to ensure satisfactory results.

In 2016 a research team from the University of Valencia and the Polytechnic University of Valencia formulated a project called MAYATECH which obtained funding from the Regional Government of Valencia (Generalitat Valenciana) under its $\mathrm{R}+\mathrm{D}+\mathrm{i}$ programme for groups of excellence (PROMETEO).

The main objective of the project was to combine the use of new technologies and traditional techniques in order to document in an accurate way some of the most notable buildings located in the World Heritage Cities of the Maya Area. The work was to be complemented with archaeometry and iconography studies.

The project provided the local authorities and institutions responsible for this architectural heritage with high-quality documentation to enable them to draw up effective preventive conservation strategies for these notable examples of Maya architecture within a development perspective, placing the emphasis on sustainability at all times.

This pilot project developed a precise and efficient methodology which was applied in selected buildings. In future work, this methodology will be implemented across the board.

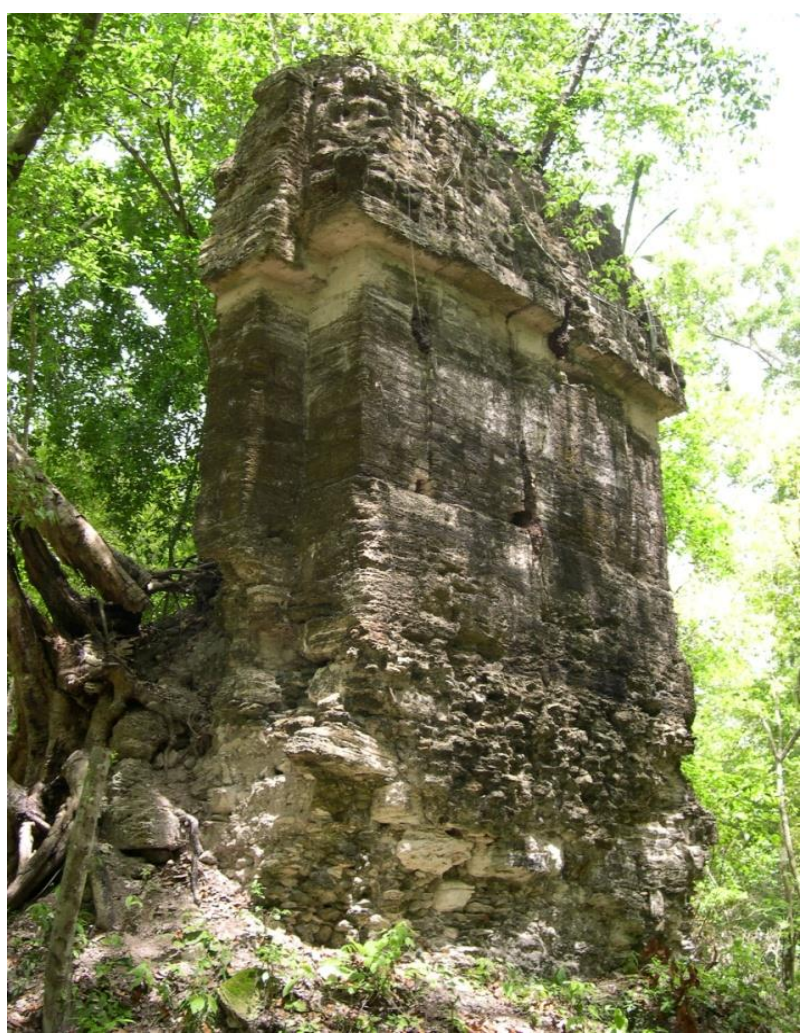

Figure 2. Looted and eroded building at Corozal Torre, in the rainforest, Petén, Guatemala. (Photo G. Muñoz 2003).

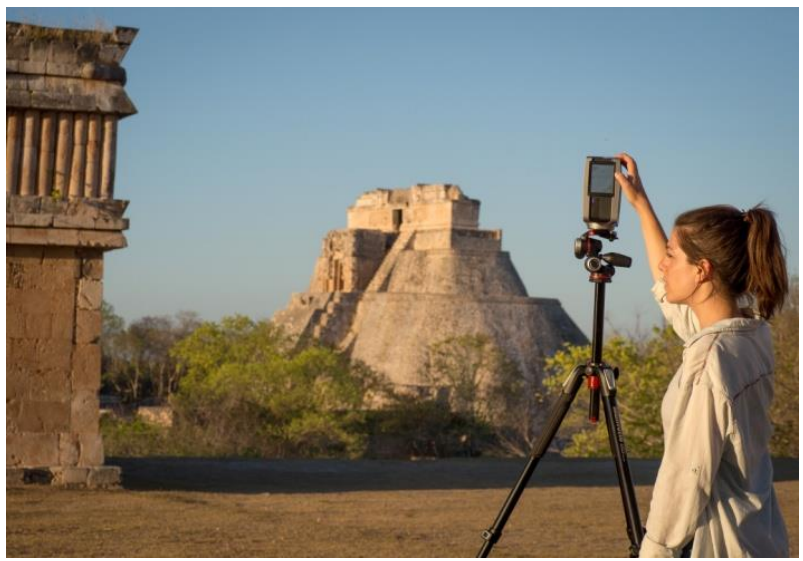

Figure 3. Laser scanning data capture at Uxmal, Mexico. (Photo R. Martínez 2018).

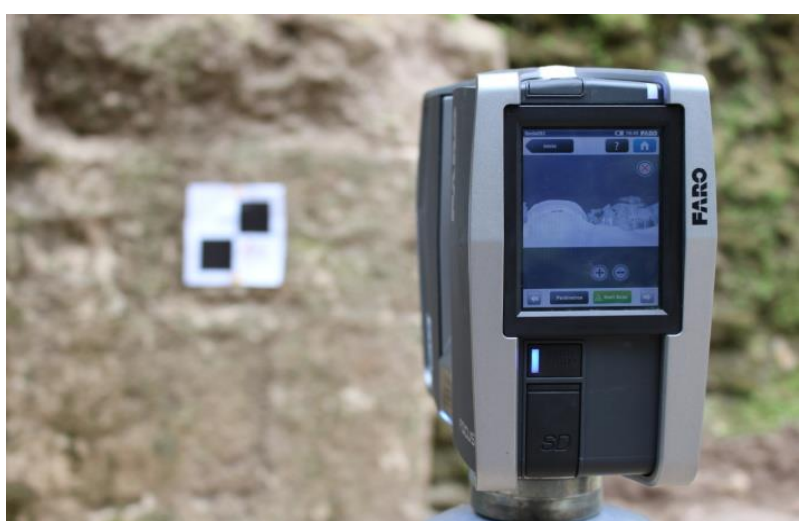

Figure 4. Data capture with a FARO Focus 3D S120 laser scanner, using bidimensional reference targets. (Project La Blanca 2015) 


\subsection{Criteria and Methodology}

The first objective is to survey the building and to obtain morphological data, at an appropriate and quantifiable scale, together with complementary chromatic information that allows high quality definition of the external texture of each of its parts. The analysis of the building's state of conservation can then be addressed.

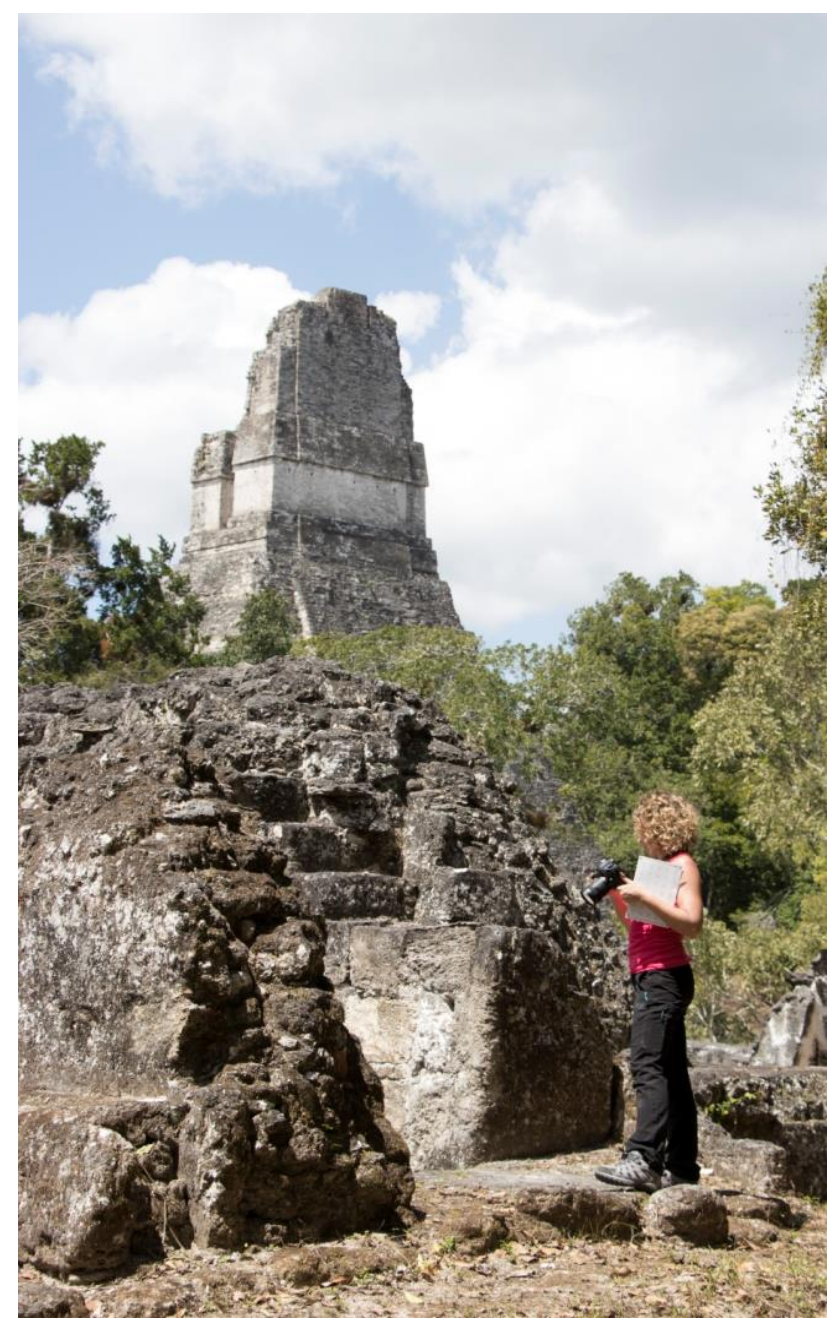

Figure 5. Photogrammetric survey at Tikal, Guatemala. (Photo C. Vidal 2017).

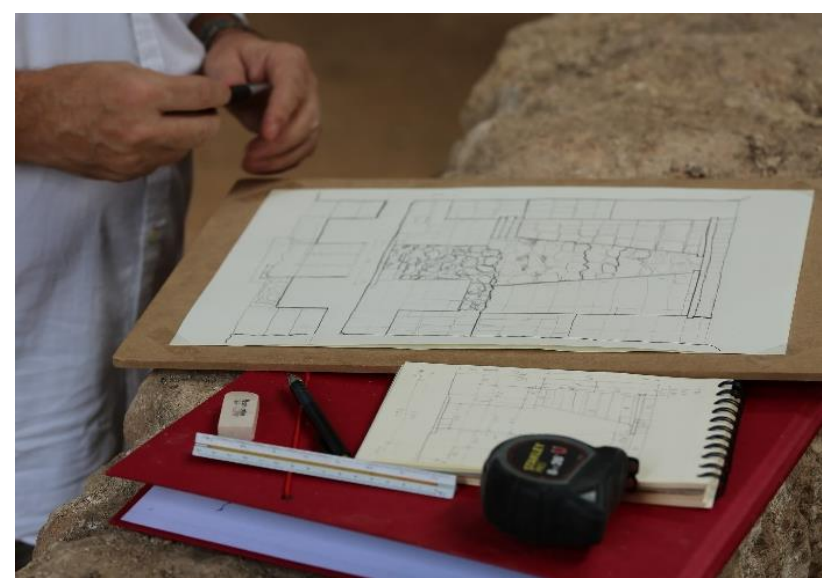

Figure 6. Traditional freehand sketching at Uxmal, Mexico. (Photo C. Vidal 2019).
This integrated architectural survey applies a range of methodologies and complementary tools. A laser scanner is used to record data in the field, both inside and outside the building, using aligned point clouds to obtain a high precision geometric definition. This provides a very accurate planimetric restitution of the building and makes it possible to create a 3D model. The information contained in the aligned point clouds can be consulted later to establish possible modifications or alterations. At the same time, a detailed photogrammetric survey is carried out to obtain an in-depth restitution of the texture and surface of all the materials and the different parts of the building, providing detailed information on the colours of the building and the texture of its different elements. This allows a planimetric study by means of high quality orthophotos showing all the alterations and modifications, which serves to establish an analysis of the building's state of conservation and to make an adequate diagnosis.

In addition to these two techniques, data are also compiled via traditional methods such as freehand sketching and direct measurement, as well as in-depth drawing of architectural details and of the most complex areas of the building. A complementary photographic survey of the most significant aspects is also carried out, especially the ones that are likely to present particular difficulties when performing the planimetric and formal restoration of the building.

Continuing on from the work done in phase 1, in the second phase we carry out the desktop work that should produce the complete architectural plan of the building at different scales, including floors, elevations and sections. The elevations and photogrammetric sections incorporate high quality orthophotos that faithfully reflect the texture and colour, and make it possible to produce a textured $3 \mathrm{D}$ model that provides a virtual image of the building.

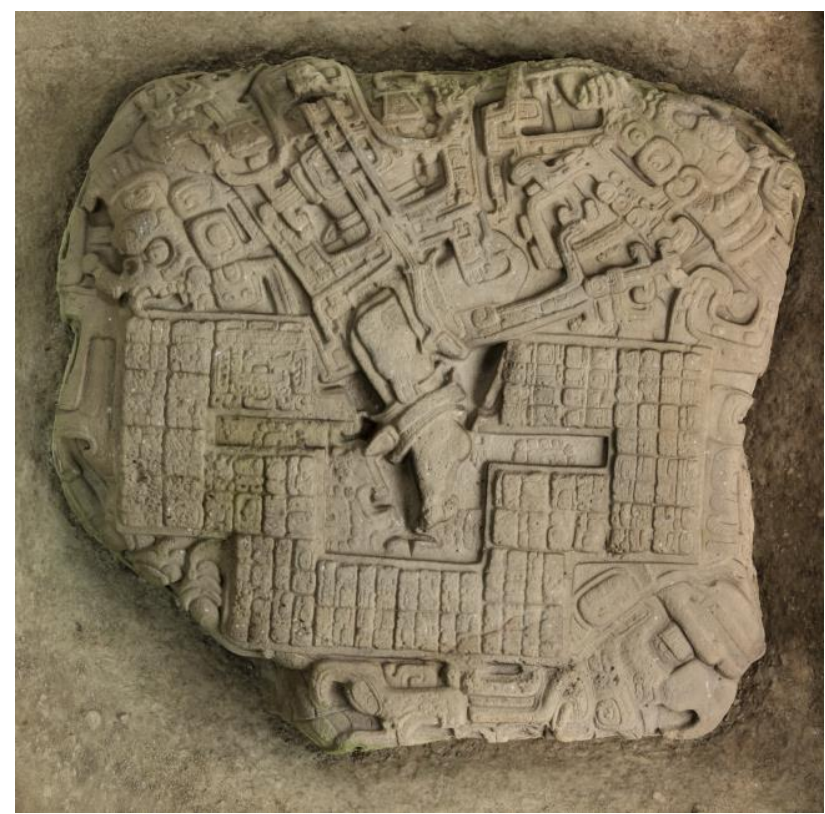

Figure 7. Photogrammetric image of Altar P of Quiriguá, Guatemala. (Project MAYATECH 2018).

Whenever possible, archaeometric analysis of materials and pigments is carried out to provide additional information about the building's characteristics or history. An iconographic analysis of the artistic manifestations present in the building's facades or interior is also planned. 


\section{THE PALACE OF THE GOVERNOR AT UXMAL}

The city of Uxmal is one of the most important archaeological sites of the Northern Maya Lowlands. It is located in the Puuc area in the Yucatán Peninsula (Mexico). The regularity of its layout and the spectacular architecture that is still preserved is testimony to its architectural and urban value. Its best known buildings are the extraordinary complex of the Nunnery Quadrangle, the Pyramid of the Magician, the House of the Turtles or the Palace of the Governor.

These two last buildings, both built on the same platform, were chosen as the starting-point for our documentation project in this city. Fieldwork was carried out in two seasons: ten days in April 2018 and one week in November 2019. Data were collected using a laser scanner, both inside and outside the buildings, and in the photogrammetric survey.

The methodology described above was complemented by a traditional survey in the form of sketches and drawings made with precision tools. The information recorded was processed and a body of high quality architectural documentation was obtained.

Below we explain in detail our work at the Palace of the Governor.

\subsection{The building}

The Palace of the Governor is $98 \mathrm{~m}$ long and $12 \mathrm{~m}$ wide, covering an area of approximately $1200 \mathrm{~m}^{2}$, and is $9 \mathrm{~m}$ high. It is located on a stepped platform, with grand central staircase to the east, that supports the building, which is $122 \mathrm{~m}$ long and 32 $\mathrm{m}$ wide and rises $7 \mathrm{~m}$ above the large basal platform. The basal platform is approximately $170 \mathrm{~m}$ long and $150 \mathrm{~m}$ wide, covering an area of 2.5 hectares.

The Palace comprises three sections: a central building, two corbel-vaulted arches, and two side buildings.

The central building is $55 \mathrm{~m}$ long with 10 interior rooms distributed in two bays, one behind the other. The rooms of the inner bay are accessed from the room located on the front bay by an interior door. The main facade has seven doorways, the three central ones belonging to the central room, which is the largest, together with the central rear room, but they have different widths: the rooms of the inner bay are widest, almost 4 $\mathrm{m}$ wide. The other four doorways led to the side rooms.

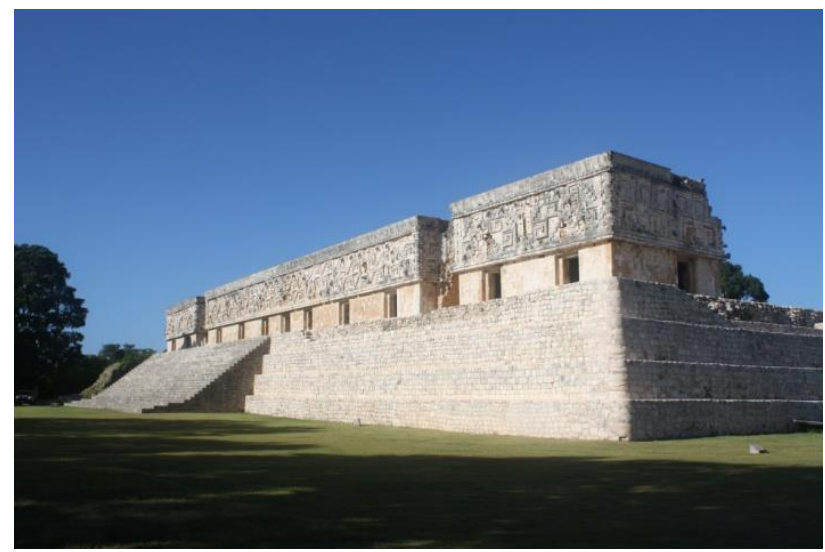

Figure 8. The Palace of the Governor at Uxmal, Mexico. (Photo G. Muñoz 2016).

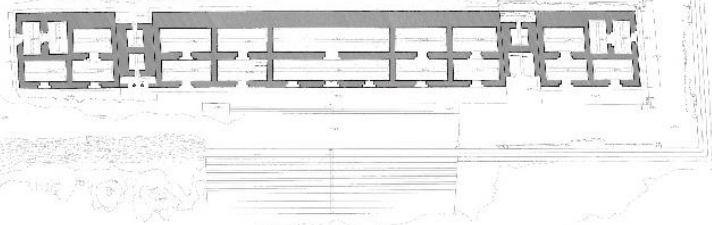

Figure 9. Floor plan of de Palace of the Governor. (Project MAYATECH 2019).

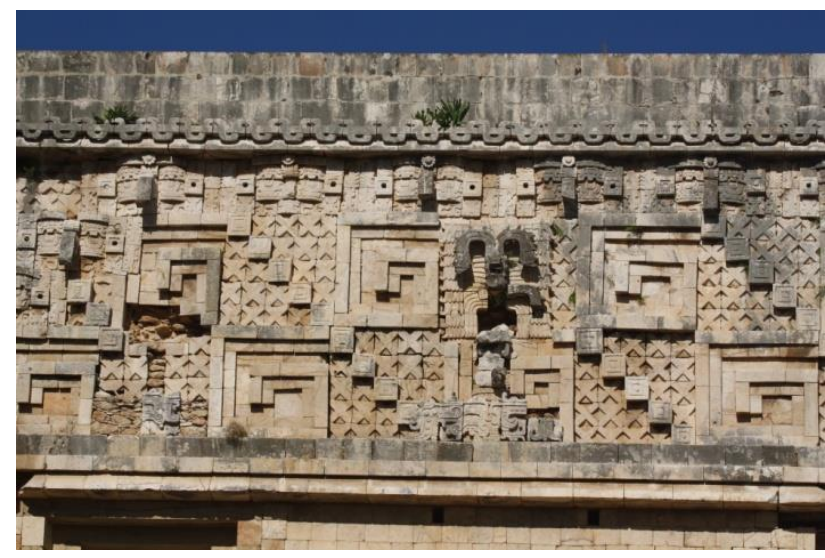

Figure 10. Detail of the Palace of the Governor's upper frieze. (Photo G. Muñoz 2016)

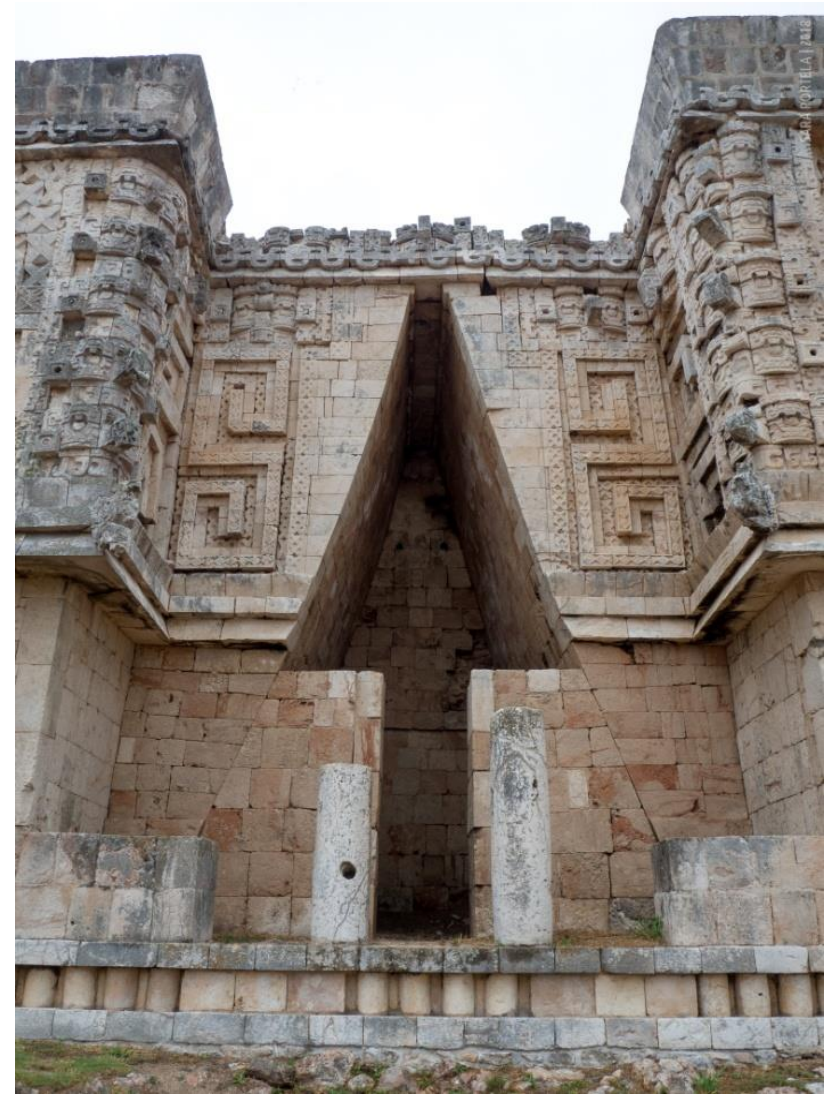

Figure 11. South corbel-vaulted arch at the front facade of the Palace of the Governor. (Photo G. Muñoz 2016). 
The corbel-vaulted arches were probably once two corbelvaulted passageways, serving as convenient passages between the main and the rear facades. They also join the central building with the side buildings. These imposing structures are more than $4 \mathrm{~m}$ wide and have an interior height of $6.74 \mathrm{~m}$. They were later divided by a central wall; additional building elements were attached to them to form two rooms, each one facing one of the facades.

Each of the side buildings has five rooms. Three of them are accessed by two doorways located on the eastern facade and the two others by a doorway located on the north and south facade of the building respectively.

The building has a total of eleven doorways to the east, one to the south and one to the north. The rear facade, to the west, has no doors. It has a total of 24 rooms: 20 inner vaulted rooms and the four rooms created by the division of the two corbel-vaulted passageways.

The building's facade comprises a lower moulding or skirting board decorated with junquillos, a middle moulding and an upper moulding or cornice. The lower wall face measures 2.60 $\mathrm{m}$ approx. and the frieze, between the middle and upper moulding, $3.50 \mathrm{~m}$. It is decorated with a high quality stonemosaic work characteristic of the Late Puuc style. The quality of the limestone, the care and finesse of its carving and the modular composition of its mosaic frieze make this building a striking example of the Puuc style in its final stages, known as Late Uxmal style.

\subsection{Laser scanner data capture and data processing}

The survey of the Palace of the Governor was carried out with a Faro Focus 3D S120 laser scanner, and $160 \mathrm{~mm}$ reference spheres were used to allow the correct collimation of the point clouds. The spheres were positioned to be visible in almost all the scans, especially those located behind the palace, in the passage from the outside to the inside of the building. These references provide highly accurate geometrical definition and reflectance values, thus aiding recognition by the postprocessing algorithm and reducing computation time (Vidal, Muñoz, Merlo, 2017, p. 266).

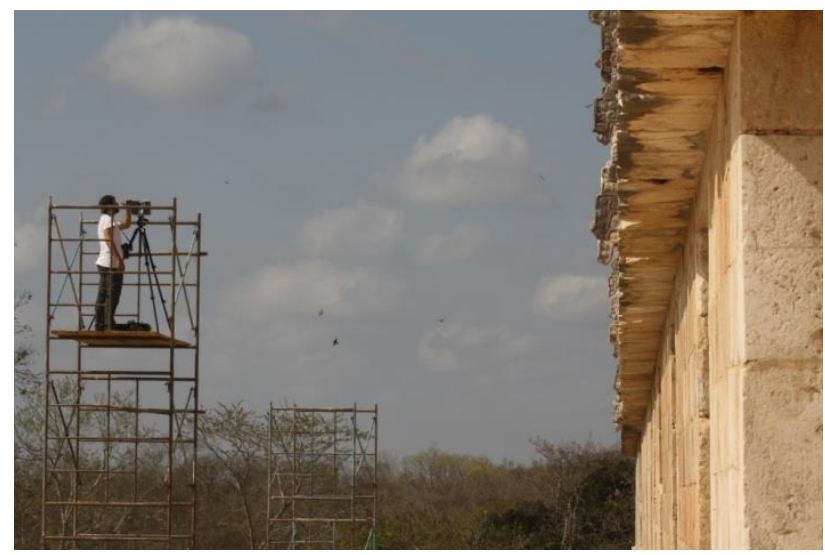

Figure 12. Laser scanner data capture from the scaffolding tower. (Photo G. Muñoz 2018).

Scaffolding was used to avoid leaving any areas of the upper facades unscanned. Twenty temporary scaffolding towers were erected successively on the base platform of the building in order to carry out all the scans required. Special care was taken to ensure that the scanner remained in a stable position.
Several scans were also undertaken on the roof and particularly on its edges, in order to obtain evidence of all the upper elements of the facades.

Colour photographs were taken by the laser scanner's internal photo-camera in order to record the chromatic aspect of the building. Nevertheless, these photographs were only used to allow an understanding of the architectonic complex during data processing; to obtain the real colour and the texture of the different parts of the building, a photogrammetric survey is necessary.

The information obtained in the fieldwork was then processed in desktop work. The point clouds were aligned by using semiautomatic tools for the recognition of the reference spheres. These tools were provided by the software Faro Scene, a programme specifically developed for $3 \mathrm{D}$ point cloud processing and managing (Vidal, Muñoz, Merlo, 2017, p. 266). The average deviation error was maintained below $3 \mathrm{~mm}$. A geometrically faithful 3D model of the whole building was created.

These data were subsequently exported to other software for the preparation of the sections required to draw the architectural planimetry, following the traditional method of graphic representation using orthogonal projections.

\subsection{Digital photogrammetric survey}

The photogrammetric survey was carried out simultaneously with the laser scanner, both outside and inside the Palace of the Governor, using a digital reflex camera Canon 5D Mark 111 with a Canon EF 24-105 mm f/3.5-5.6 IS STM lens. A colourchecker OpCard 202 was placed in each scene, which is essential to set the white balance of the photographs. A Sonnon DL-913/DL-Simple Model continuous light LED spotlight and a tripod were used in the interior rooms to guarantee optimal time exposure.

The photogrammetric survey consists of more than 15000 photographs in RAW format taken with an adequate horizontal and vertical overlap between them, in order to obtain a reconstruction of the photogrammetric model and a high quality view of the texture at a scale of 1:50.

After the alignment of the photogrammetric models to the general reference system, and through a careful analysis of the architectural and sculptural elements, the model was developed by subdividing it into different parts, depending on the level of detail required. The photogrammetric models generated were finally integrated and coordinated with the planimetric survey in order to achieve the expected final result with a graphic quality, colouring and texture as close as possible to reality.

\subsection{Additional survey with traditional systems}

The methods used in previous work have achieved results of high quality and precision. However, as often occurs during the graphic restitution and the planimetric drawing in desktop work, some problems may arise when the photogrammetry or the point clouds show uncertainties in specific areas which are difficult to solve using these powerful tools alone. Accordingly, the general strategy of the present study includes a traditional survey with freehand sketching and direct measurements in order to broaden our knowledge of the most complex areas of the building. The greatest difficulty in the case of the Palace of the Governor was to understand the complex cutting of the carved limestone in its mosaic frieze, with its particular way of fitting all the pieces together, and the description of each one. 


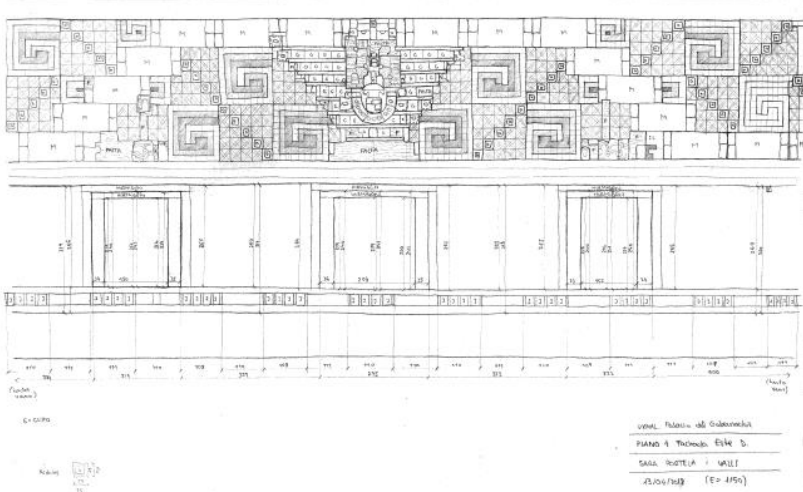

Figure 13. Hand sketch of the Palace of the Governor's front facade central elevation. (Project MAYATECH 2018).
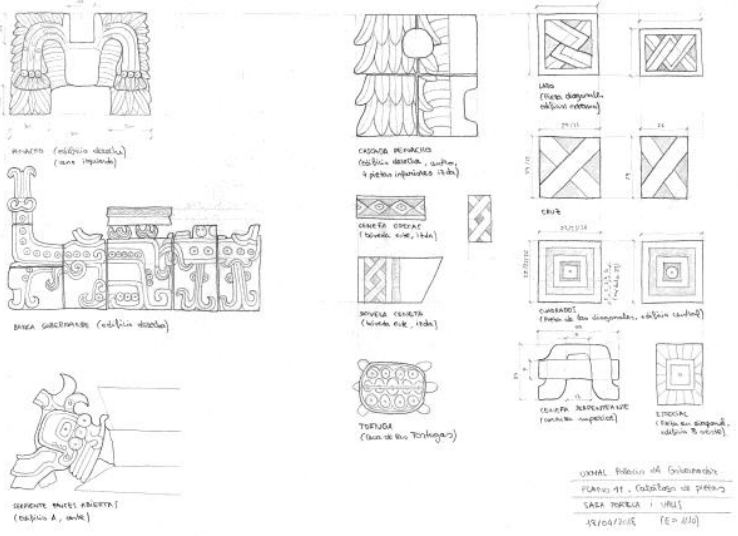

Figure 14. Hand sketch of some carved mosaic-stones of the frieze. (Project MAYATECH 2018).

\subsection{Results}

The final objective of the process is to obtain the architectural planimetry of elevations, sections, floors and details, drawn digitally according to traditional architectural methods, at different scales, and to provide a complete architectural view of the building.

The same planimetry will also be obtained by using the photogrammetry superimposed on the point cloud model, achieving elevations, sections and floors with a high quality view of the texture and colour of the building.

A 3D model can also be obtained by using the appropriate software, starting from the aligned point clouds and following a process of creating polygons by triangulating the points and then simplifying them to obtain a threedimensional surface on which to project the texture and colour produced by the photogrammetric data. The planimetric documentation can be enriched by the abundant photographic documentation that allows a complete and indepth analysis of all parts of the building. It also provides a documentary archive of its current state that will allow us to check faithfully any future deformation or alteration of the Palace of the Governor.
Furthermore, augmented reality visualizations of the building can be obtained with the 3D model, allowing observers to experience the spatial and architectural dimensions of the Palace of the Governor as if they were in the presence of the real building. This approach opens up a range of possibilities for ways to promote the region's cultural heritage.

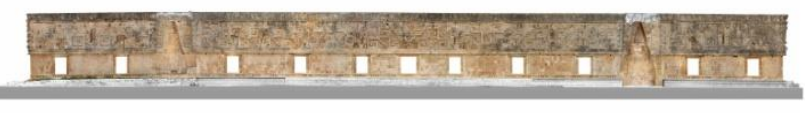

Figure 15. Photogrammetric view of the Palace of the Governor's front facade elevation. (Project MAYATECH 2019).

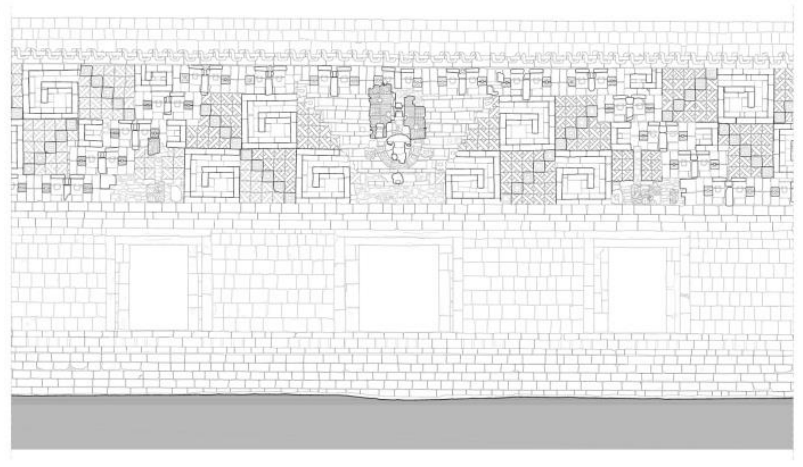

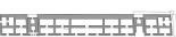

Figure 16. Digital architectonic drawing of the Palace of the Governor's front facade central elevation. (Project MAYATECH 2019).
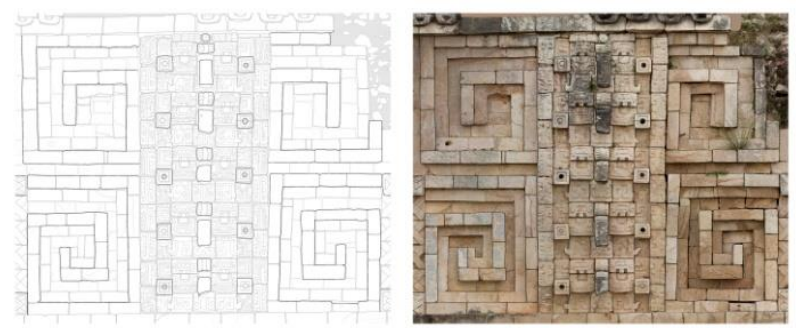

Figure 17. Architectonic and photogrammetric restitution of the Palace of the Governor's frieze. Detail. (Project MAYATECH 2019).

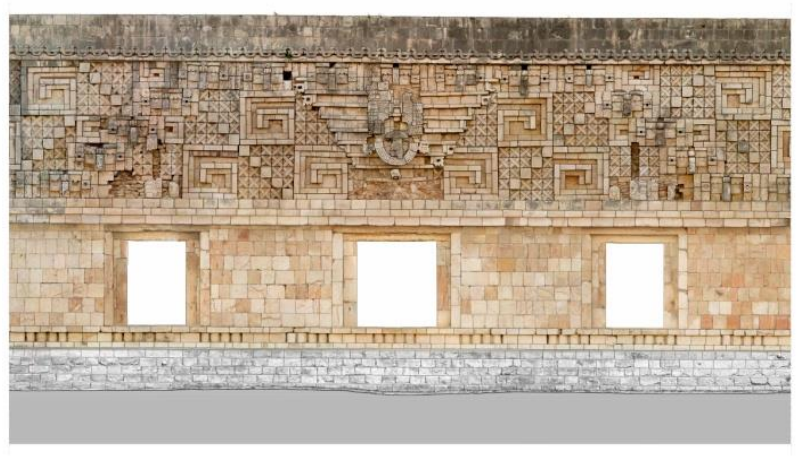

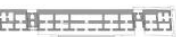

Figure 18. Photogrammetric view of the Palace of the Governor's front facade central elevation. (Project MAYATECH 2019). 


\section{CONCLUSIONS}

The work carried out at the Palace of the Governor of Uxmal has shown that it is possible to produce an exhaustive body of documentation on a complex architectural object in a highly active natural environment. This project provides easily accessible and user-friendly digital and printed materials that faithfully reflect the current state of conservation of this building. But these documents are not just "static photographs": all the other information obtained, like the point clouds and photogrammetric data, comprises a vast set of archived evidence that might allow us in the future to check some specific features that existed at the moment of the data capture, enabling us to trace any changes and modifications occurring at the Palace of the Governor that emerge from new observations or data collection.

Undoubtedly, these digital tools offer a wide range of opportunities and new alternatives for the meticulous documentation of the Maya archaeological and architectural heritage. At the same time, they encourage new interpretations and helping to bring this heritage to a much wider audience.

\section{ACKNOWLEDGMENTS}

This research would not have been possible without the support of: The Generalitat Valenciana (Project Mayatech-Prometeo 2016/155); The Spanish Ministry of Science, Innovation and Universities through the funding of various coordinated research programs (reference numbers BIA2011-28311-C02, BIA2014-53887-C2 and PGC2018-098904-B-C2), as well as the support of the archaeologist José G. Huchim at Uxmal (Mexico) and Eduardo López Calzada, delegate of the Instituto Nacional de Antropología e Historia at Yucatán (Mexico). Special thanks also to the team of Project Mayatech at Uxmal: Riccardo Montuori, Rosana Martínez Vanaclocha, Sara Moreno Sánchez, Silvia Puerto Aboy, Sara Portela i Valls, Héctor Cauich Caamal, Patricia Valencia Santiago and Luis Fernando Cruz Pacheco.

\section{REFERENCES}

Vidal Lorenzo, C., Muñoz Cosme, G. y Merlo A., 2017: Surveying Ancient Maya Buildings in the Forest. En Ippolito A. (Ed), Emerging Technologies for Architectural and Archaeological Heritage, pp. 255-290. Hersehy: IGI Global. 